Check for updates

Cite this: RSC Adv., 2018, 8, 6406

\title{
Effects of shear on epitaxial crystallization of poly( $\varepsilon$-caprolactone) on reduced graphene oxide
}

Received 19th December 2017 Accepted 2nd February 2018

DOI: 10.1039/c7ra13442h

rsc.li/rsc-advances

\author{
Feng Wu, ${ }^{a}$ Libin Jiang, ${ }^{a}$ Weijun Miao, (D) a Tianchen Duan, ${ }^{a}$ Minfang An, ${ }^{a}$ Feng Tian $^{\mathrm{b}}$ \\ and Zongbao Wang $\mathbb{1}$ *a
}

Epitaxial crystallization of poly( $\varepsilon$-caprolactone) $(\mathrm{PCL})$ on reduced graphene oxide $(R G O)$ was investigated by shearing at different shear rates of $3 \mathrm{~s}^{-1}$ and $75 \mathrm{~s}^{-1}$ and different shear temperatures of $65{ }^{\circ} \mathrm{C}, 70^{\circ} \mathrm{C}$ and $75{ }^{\circ} \mathrm{C}$, respectively. Two dimensional wide angle X-ray diffraction (2D WAXD) results show that the crystallinity and the orientation degrees of the (110) plane of PCL/RGO nanocomposites with shear are higher than those without shear, but the imposed shear field has no obvious effect on the crystal structure of the PCL matrix. Two dimensional small angle X-ray scattering (2D SAXS) results suggest that the imposed shear field makes PCL chains epitaxially crystallize on RGO surfaces to form thicker lamellae. Thereby the melt points of PCL/RGO nanocomposites with shear are higher than that without shear from the differential scanning calorimetry (DSC) results. These results indicate that the imposed shear field can enhance the orientation of the PCL matrix, and promote epitaxial crystallization of $\mathrm{PCL}$ chains on RGO surfaces. Higher shear temperature is the requirement for PCL chains to epitaxially crystallize well on RGO at low shear rate, although it is not required for the samples at high shear rate.

\section{Introduction}

Owing to their inherent mechanical properties and high surface area, nanosized reinforcing fillers have attracted great interest in the field of composite materials. Polymer nanocomposites can possess enhanced properties through nanoscale reinforcement compared with conventional filled polymers or polymer blends. ${ }^{1-4}$ In recent years, more and more nanosize inorganic materials acting as fillers have been used in the preparation of polymer/inorganic nanocomposites, which is due to their unique properties and numerous potential applications. ${ }^{5,6}$

Two-dimensional (2D) layered nanofillers can more intentively improve mechanical, physical and thermal properties of polymer matrices, comparing to zero-dimensional nanofillers and one-dimensional nanofillers. ${ }^{7}$ These $2 \mathrm{D}$ layered nanofillers could effectively enhance the orientation of polymer chains in the nanofiller network. ${ }^{8}$ As the strongest material found as yet (ultimate strength, $130 \mathrm{GPa}$; Young's modulus, $1 \mathrm{TPa}$ ), ${ }^{9,10}$ graphene is a two-dimensional, atomically thick sheet composed of $\mathrm{sp}^{2}$ carbon atoms arranged in a honeycomb structure. ${ }^{11-15}$ Hence, graphene has great potential for improving the mechanical properties of polymer. ${ }^{16-18}$ It has been reported that graphene could significantly improve the mechanical properties of polyesters such as poly( $\varepsilon$-caprolactone) (PCL), poly(3-

${ }^{a}$ Ningbo Key Laboratory of Specialty Polymers, Faculty of Materials Science and Chemical Engineering, Ningbo University, Ningbo 315211, PR China. E-mail: wangzongbao@nbu.edu.cn

${ }^{b}$ Shanghai Institute of Applied Physics, Chinese Academy of Sciences, Shanghai 201204, PR China hydroxybutyrate) (PHB), poly(L-lactic acid) (PLA), and poly(3hydroxybutyrate-co-3-hydroxyvalerate) (PHBV). ${ }^{19-22}$ It is wellknown that not only the mechanical properties and dispersion of nanofillers in the polymer but also the interaction between polymer and nanofillers have great influences on the mechanical properties of polymer/nanofiller composites. Thus, great effort has been devoted to improving the interaction between graphene and polymer matrixes. It has been reported that graphene can be modified by surface chemical functionalization with functional groups, such as small molecules ${ }^{23,24}$ and polymer chains, ${ }^{25,26}$ which can improve the solubility and processability markedly to enhance the interaction with polymers. ${ }^{27}$ However, the conjugation of the graphene sheet is disrupted and the mechanical properties of the chemically modified graphene decreased dramatically, which is due to the break of $\mathrm{sp}^{2}$ conformation of the carbon atom in graphene resulting from the chemical reaction. ${ }^{28}$ Thus, it is very essential to find a physical way with no damage for the structure of graphene in polymer/graphene composites. Fortunately, interfacial crystallization offers a possible means to enhance polymer/ nanofiller interfacial interaction in composite systems composed of semi-crystalline polymer and fillers with high aspect ratio. ${ }^{29}$ Obviously, the formation of an interfacial crystalline layer can offer a good interfacial combination between graphene and polymer matrix..$^{30,31}$ However, most researchers still use the traditional methods to improve the interface adhesion of polymer/graphene nanocomposites. ${ }^{32}$ Petermann et al. reported that epitaxial interfaces with strong adherence were responsible for the improvement of the mechanical 
properties of polymer/graphene composites. ${ }^{33-35}$ In our previous work, poly( $\varepsilon$-caprolactone) (PCL)/reduced-graphene oxide (RGO) nanocomposites with epitaxial interaction were prepared, indicating that the incorporation of RGO can enhance the crystallization and orientation of PCL matrix, which was the major factor for the improvement of mechanical properties. ${ }^{36,37}$

Epitaxy, meaning “on arrangement”, is defined generally as the crystals of one phase (guest crystals) grown on the surface of a crystal of another phase (host crystal) in one or more strictly defined crystallographic orientations. ${ }^{38,39}$ According to previous studies, ${ }^{\mathbf{4 0 - 4 2}}$ the occurrence of polymer epitaxy is based on some certain crystallographic matches, namely, a coincidence of unit cell dimensions, and the highest limit for the occurrence of the epitaxial growth is assumed to be $15 \%$. $^{43}$

As we all know, shear stress field can markedly affect the crystallization, orientation and the resulting mechanical properties of semi-crystalline polymer. ${ }^{\mathbf{4 4 , 4 5}}$ Kelarakis et al. reported that the amount of shear induced oriented crystals increased with the modified carbon fiber (CF) concentration in isotactic polypropylene/modified CF composites, suggesting that the CF hindered the motion of polymer chains and increased their relaxation time. ${ }^{46} \mathrm{Su}$ et al. reported that shear-induced crystallization could improve the mechanical properties of injectionmolded bars of high density polyethylene/isotactic polypropylene blend. ${ }^{47}$

In this work, we further study influence of the imposed shear field on the epitaxial crystallization of PCL on RGO surface. PCL/0.5 wt\% RGO nanocomposite sheets were sheared at specified shear rates and temperatures. Differential scanning calorimetry (DSC), two dimensional wide angle X-ray diffraction (2D WAXD) and two dimensional small angle X-ray scattering (2D SAXS) measurements were applied to investigate the structural mechanism of epitaxial crystals of PCL on RGO produced by imposed shear field.

\section{Experiment section}

\subsection{Materials}

PCL was purchased from Shanghai Yizhu Co., Ltd. (Shanghai, China), with average weight $M_{\mathrm{n}}=42500 \mathrm{~g} \mathrm{~mol}^{-1}$ and polydispersity index $M_{\mathrm{w}} / M_{\mathrm{n}}=1.5$. Natural flake graphite was purchased from Qingdao Jiuyi graphite Co., Ltd. (Shandong, China) with a mean particle size of $50 \mu \mathrm{m}$. Hydrochloric acid ( $\mathrm{HCl})(37 \%)$, sulfuric acid $\left(\mathrm{H}_{2} \mathrm{SO}_{4}\right)(98 \%)$, potassium nitrate $\left(\mathrm{KNO}_{3}\right)$, potassium permanganate $\left(\mathrm{KMnO}_{4}\right)$, hydrogen peroxide $\left(\mathrm{H}_{2} \mathrm{O}_{2}\right)(35 \%)$, $n$-hexanol and chloroform were purchased from Sinopharm Chemical Reagent Co., Ltd. (Shanghai, China). All reagents were used as received without further purification.

\subsection{Preparation of PCL/RGO nanocomposite}

Graphene oxide (GO) was exfoliated by ultra-sonication from graphite oxide which was produced by modified Hummers method. ${ }^{48}$ RGO was prepared by thermal exfoliation and reduction of GO. ${ }^{49}$

Poly( $\varepsilon$-caprolactone) $/ 0.5 \mathrm{wt} \%$ reduced-graphene oxide (PCL/ $0.5 \mathrm{wt} \%$ RGO) nanocomposite was melt mixed at $90{ }^{\circ} \mathrm{C}$ in
HAKKE Minilab for 3 minutes, making them pieces with the thickness of $0.5 \mathrm{~mm}$.

\subsection{Analytical methods}

A Linkam CSS 450 high temperature shearing stage modified for X-ray scattering/diffraction studies was used for SAXS and WAXD experiments. The X-ray modification included the use of a diamond window and a Kapton film to replace the standard quartz windows at the entrance and exit of the X-ray beam through the sample. The detailed modification has been described in detail in elsewhere. ${ }^{\mathbf{5 0}, 51}$ Typically, a pressed polymer ring, diameter $=20 \mathrm{~mm}$ and thickness $=0.5 \mathrm{~mm}$, was mounted between the two parallel plates (X-ray windows) of the shear stage. ${ }^{52}$ The parallel plate geometry was used. The electronic and mechanical accessories of this stage allowed an accurate control over a number of experimental parameters such as sample, shear temperature, heating/cooling rate, applied shear strain, and duration. Prior to shear, the sample was subject to a thermal treatment in order to ensure that the polymer was free of any memory effects associated with clusters, crystal aggregates and molecular conformation.

The experimental protocol was used in the shear studies consisted of the following discrete steps:

(1) Sample was heated from room temperature to $90{ }^{\circ} \mathrm{C}$ (above the equilibrium melting point of PCL, $T_{\mathrm{m}}=60^{\circ} \mathrm{C}$ ) at the rate of $30{ }^{\circ} \mathrm{C} \mathrm{min}^{-1}$.

(2) Hold the temperature at $90{ }^{\circ} \mathrm{C}$ for $3 \mathrm{~min}$.

(3) Cool the sample to $65{ }^{\circ} \mathrm{C}, 70{ }^{\circ} \mathrm{C}$ and $75^{\circ} \mathrm{C}$ with the cooling rate of $30{ }^{\circ} \mathrm{C} \mathrm{min}^{-1}$, respectively, and then shear the sample at the shear rates of $3 \mathrm{~s}^{-1}$ and $75 \mathrm{~s}^{-1}$ for $100 \mathrm{~s}$, respectively.

(4) After shearing, cool them to $30{ }^{\circ} \mathrm{C}$ at the rate of $30{ }^{\circ} \mathrm{C} \min ^{-1}$.

2D SAXS experiments were carried out on the BL16B1 beam-line in the Shanghai Synchrotron Radiation Facility (SSRF). The 2D patterns were recorded in transmission mode at room temperature and the sample-to-detector distance was $2200 \mathrm{~mm}$. The X-ray wavelength was $0.1239 \mathrm{~nm}$ and the beam size was $0.4 \mathrm{~mm}(\mathrm{H}) \times 0.5 \mathrm{~mm}(\mathrm{~V})$. 2D SAXS patterns were collected by using a Mar CCD X-ray detector (MAR165), having a resolution of $2048 \times 2048$ pixels. The beam intensity monitor before sample was a $\mathrm{N}_{2}$ gas ionization chamber, and the monitor after sample adsorption was a photodiode in the beam stop.

2D WAXD experiments were carried out on the two scatterless slits (Xenocs). WAXD curves were collected from the 2D WAXD patterns. The wavelength of the monochromatic X-ray was $0.15418 \mathrm{~nm}$. The $2 \mathrm{D}$ diffraction patterns were recorded in transmission mode at room temperature. X-ray patterns of the standard samples, silver behenate and $\mathrm{CeO}_{2}$, were used for calibration of sample to detector distance for WAXD.

All X-ray data was corrected for background (air and instrument) scattering before analysis. The SAXS and WAXD data analysis was performed out by using the Fit2d software package. ${ }^{53}$ The lamellae parameter derived from the SAXS data is named the long period $L$. It can be calculated according to the Bragg equation: 


$$
L=2 \pi / q^{*}
$$

where $q^{*}$ is the peak position in the scattering curves.

In WAXD analysis, the degree of crystal orientation was obtained by using the Herman's method. ${ }^{54}$ In specific, the degree of orientation, $f_{110}$, was calculated from the azimuthal intensity distribution, $I(\varnothing)$, of the (110) crystal reflection. The crystallinity was calculated according to the diffraction intensity of crystal phase and amorphous phase, and the diffraction intensity was obtained through the integration from azimuthal angle of 0 to 180 degree.

Differential scanning calorimetry (DSC) measurements were performed with Perkins Elmer DSC8000 under nitrogen atmosphere. The samples without shear and with shear were cut into pieces weighting to $5-8 \mathrm{mg}$, and then all samples were heated to $90{ }^{\circ} \mathrm{C}$ at a heating rate of $10{ }^{\circ} \mathrm{C} \mathrm{min}^{-1}$.

\section{Results and discussion}

\subsection{WAXD analysis}

Fig. 1 shows 2D WAXD patterns of PCL/RGO nanocomposites without shear and with shear at the shear rates of $3 \mathrm{~s}^{-1}$ and $75 \mathrm{~s}^{-1}$ and different shear temperatures of $65{ }^{\circ} \mathrm{C}, 70{ }^{\circ} \mathrm{C}$ and $75{ }^{\circ} \mathrm{C}$. Two diffraction rings are obviously seen in these $2 \mathrm{D}$ WAXD patterns, and the inner ring is rather wider than the outer one. And no obvious distinctions can be found from all 2D WAXD patterns in Fig. 1. WAXD curves of PCL/RGO nanocomposites without shear and with shear are collected from 2D WAXD patterns shown in Fig. 2, which indicates that PCL/RGO nanocomposites without shear and with shear show the same diffraction peaks, suggesting that the crystal structures of PCL remained unchanged despite of the imposed shear field. Notablly, three diffraction peaks observed in Fig. 2 are supposed to reflect three diffraction rings in 2D WAXD patterns. This is maybe because that the inner wide rings shown in Fig. 1 are indeed two close diffraction rings that cannot be distinguished clearly from $2 \mathrm{D}$ WAXD patterns. From the inner to outer, the diffraction rings are designated to the (110), (111) and (200) crystal planes of PCL crystals.
The crystallinity and orientation degrees of (110) plane of PCL/RGO nanocomposites without shear and with shear shown in Fig. 3 are calculated from the above 2D WAXD patterns. The crystallinity and the orientation degree of (110) plane of PCL/ RGO nanocomposites without shear are 51.56\% and 0.020 , respectively. However, the crystallinity of PCL/RGO nanocomposites sheared at the shear rate of $3 \mathrm{~s}^{-1}$ and shear temperatures of $65{ }^{\circ} \mathrm{C}, 70{ }^{\circ} \mathrm{C}$ and $75{ }^{\circ} \mathrm{C}$ are $54.96 \%, 56.89 \%$ and $58.37 \%$, respectively, which are all higher than that without shear. The orientation degrees of (110) plane of PCL/RGO nanocomposite sheared at the shear rate of $3 \mathrm{~s}^{-1}$ and shear temperatures of $65{ }^{\circ} \mathrm{C}, 70{ }^{\circ} \mathrm{C}$ and $75^{\circ} \mathrm{C}$ increase slightly to 0.024 , 0.026 and 0.029 , respectively. Obviously, the crystallinity and the orientation degree of (110) plane were enhanced by the imposed shear field. In order to further confirm that the imposed shear field has great effects on epitaxial crystallization of PCL chains on RGO surface, PCL/RGO nanocomposites were also sheared at the shear rate of $75 \mathrm{~s}^{-1}$ and above three shear temperatures. The crystallinity of PCL/RGO nanocomposites sheared at the shear rate of $75 \mathrm{~s}^{-1}$ and different shear temperatures of $65{ }^{\circ} \mathrm{C}, 70{ }^{\circ} \mathrm{C}$ and $75{ }^{\circ} \mathrm{C}$ shown in Fig. 3 are $54.38 \%$, $55.48 \%$ and $54.96 \%$, respectively. The orientation degrees of (110) plane of PCL/RGO nanocomposite sheared at the shear rate of $75 \mathrm{~s}^{-1}$ and different shear temperatures of $65{ }^{\circ} \mathrm{C}, 70{ }^{\circ} \mathrm{C}$ and $75{ }^{\circ} \mathrm{C}$ are $0.020,0.024$ and 0.022 , respectively. The crystallinity and the orientation degrees of (110) plane of PCL/RGO nanocomposites sheared at the shear rates of $3 \mathrm{~s}^{-1}$ and $75 \mathrm{~s}^{-1}$ are all higher than that of PCL/RGO nanocomposites without shear. We can also find that the crystallinity and the orientation degrees of (110) plane of PCL/RGO nanocomposites sheared at the shear rate of $3 \mathrm{~s}^{-1}$ increase with the shear temperatures, which reach to the maxima for the sample sheared at of $75 \mathrm{~s}^{-1}$ and $70{ }^{\circ} \mathrm{C}$. As for the effect of epitaxial crystallization of PCL chains on RGO surface, the shear rate of $3 \mathrm{~s}^{-1}$ was better for PCL chains to epitaxially crystallize on RGO surface than the shear rate of $75 \mathrm{~s}^{-1}$.

\subsection{SAXS analysis}

Fig. 4 shows 2D SAXS patterns of PCL/RGO nanocomposites without shear and with shear at different shear rates of $3 \mathrm{~s}^{-1}$
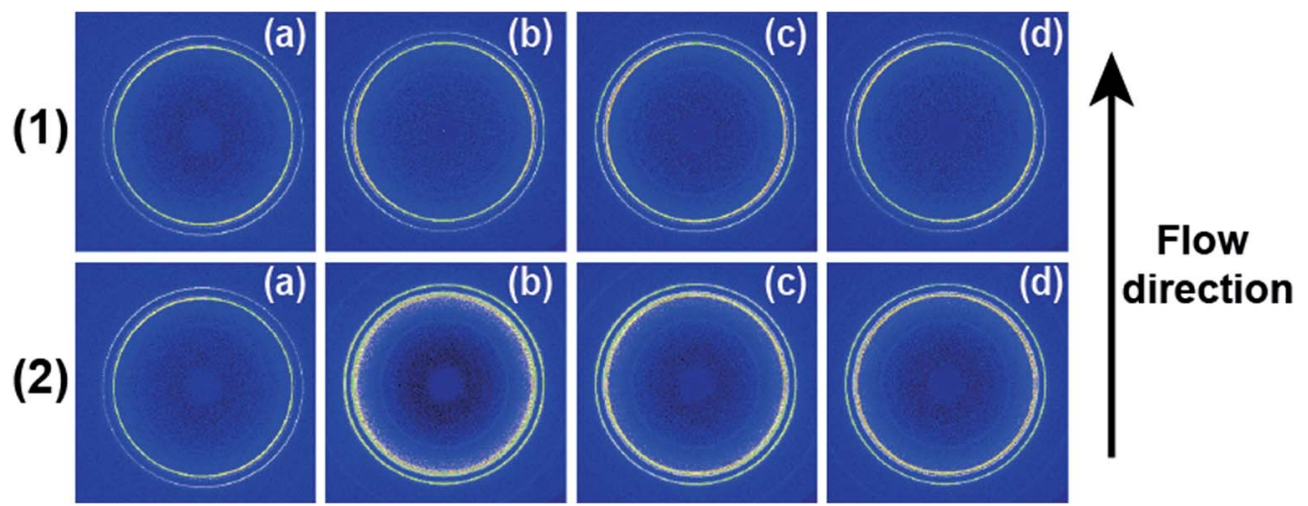

Fig. 1 2D WAXD patterns of PCL/0.5 wt\% RGO nanocomposites without shear (a) and finishing cooling crystallization with shear at different shear rates (1) $3 \mathrm{~s}^{-1}$, (2) $75 \mathrm{~s}^{-1}$ and different shear temperatures (b) $65^{\circ} \mathrm{C}$, (c) $70{ }^{\circ} \mathrm{C}$ and (d) $75^{\circ} \mathrm{C}$. The flow direction is vertical. 

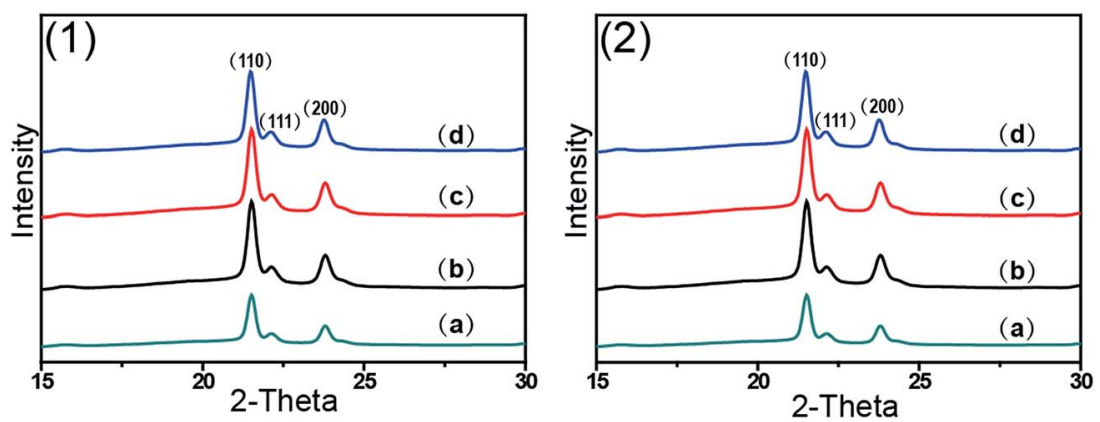

Fig. 2 WAXD curves of PCL/0.5\% wt RGO nanocomposites without shear (a) and finishing cooling crystallization with shear at different shear rates (1) $3 \mathrm{~s}^{-1}$, (2) $75 \mathrm{~s}^{-1}$ and different shear temperatures (b) $65^{\circ} \mathrm{C}$, (c) $70^{\circ} \mathrm{C}$ and (d) $75^{\circ} \mathrm{C}$.

and $75 \mathrm{~s}^{-1}$ and different shear temperatures of $65^{\circ} \mathrm{C}, 70{ }^{\circ} \mathrm{C}$ and $75{ }^{\circ} \mathrm{C}$. 2D SAXS patterns of PCL/RGO nanocomposites in Fig. 4 show qualitatively how the imposed shear field affects the evolution of oriented microstructures from the sheared melt. 2D SAXS patterns of PCL/RGO nanocomposites with shear, compared to those without shear, all have an outer scattering part, which are obviously caused by the imposed shear field. The different shear rates caused differences of these series of 2D SAXS patterns in Fig. 4. Comparing Fig. 4(1) with Fig. 4(2), we can find that these inner scattering parts of 2D SAXS patterns all show round, with no obvious differences. The scatterings of the outer parts of Fig. 4(1) show arcs, which indicates that the imposed shear field made PCL chains relatively high oriented. The appearance of scattering arc means the existence of long period with relatively high oriented. However, the scatterings of the outer parts of Fig. 4(2) show nearly round, which indicates that the imposed shear field made PCL chains low oriented. The appearance of nearly scattering round means the existence of long period with low oriented. For these 2D-SAXS patterns, meridian maxima is attributed to the layer-like oriented structures, oriented perpendicular to the flow direction. As for the effect of shear rate on epitaxial crystallization of PCL chains on RGO surface, it can be seen clearly from the 2D SAXS patterns that the shear rate of $3 \mathrm{~s}^{-1}$ has more advantages over the shear rate of $75 \mathrm{~s}^{-1}$.

1D intensity profiles are shown to quantitatively account for the effects of the imposed shear field on the nature of oriented microstructures. 1D intensity profiles of the inner and the outer part were calculated from the 2D SAXS patterns of PCL/RGO nanocomposites without shear and with shear, which can describe the effects resulted from shear rates of $3 \mathrm{~s}^{-1}$ and $75 \mathrm{~s}^{-1}$ and shear temperatures of $65{ }^{\circ} \mathrm{C}, 70^{\circ} \mathrm{C}$ and $75^{\circ} \mathrm{C}$. Fig. 5 shows the $1 \mathrm{D}$ intensity profiles of the inner intensity of PCL/RGO nanocomposites without shear and with shear. For the samples sheared at $3 \mathrm{~s}^{-1}$ (shown in Fig. 5(1)), the sharp peaks reflect the nature of the inner part in the 2D SAXS patterns, and they all shift to the direction of higher $q$ value, which is due to the fact that the imposed shear field had enhanced epitaxial crystallization of PCL chains on RGO surface. This result is also confirmed by PCL/RGO nanocomposites sheared at the shear rate of $75 \mathrm{~s}^{-1}$ shown in Fig. 5(2). There is no deny that shear rate is the more important parameter for epitaxial crystallization of PCL chains on RGO surface comparing with shear temperatures at given conditions.

As for the outer part, long period (or long spacing) between adjacent lamellae is estimated from the position of the intensity maxima along the meridian in the SAXS patterns, which is used to figure out clearly how the imposed shear field affect the epitaxial crystallization of PCL chains on RGO surface. Fig. 6 shows 1D SAXS profile curves (out part) of PCL/RGO nanocomposites sheared at the shear rates of $3 \mathrm{~s}^{-1}$ and $75 \mathrm{~s}^{-1}$ and different shear temperatures of $65^{\circ} \mathrm{C}, 70^{\circ} \mathrm{C}$ and $75^{\circ} \mathrm{C}$. The long period calculated from Fig. 6 indirectly implies the effect of the imposed shear field on the epitaxial crystallization of PCL chains on RGO surface. The long periods of PCL/RGO nanocomposites sheared at the shear rate of $3 \mathrm{~s}^{-1}$ are calculated to be
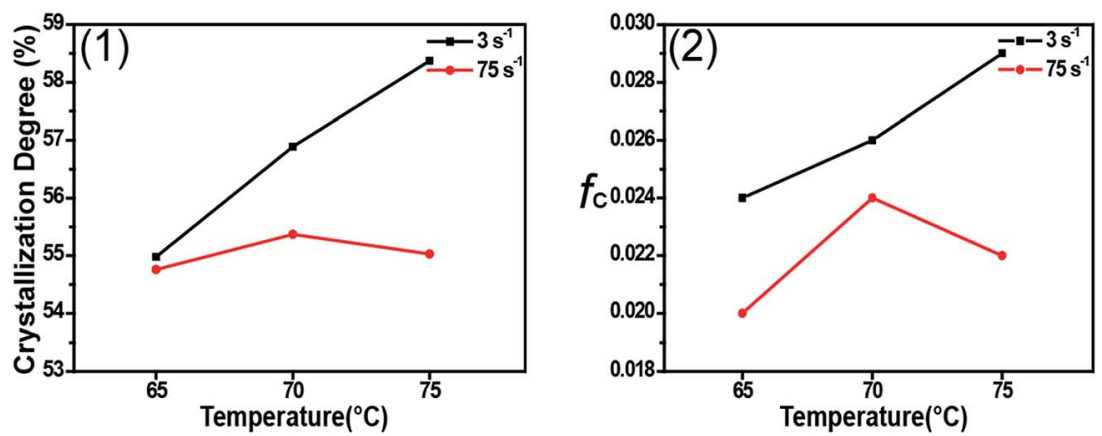

Fig. 3 The crystallinity (1) and the orientation degree of (110) plane (2) of PCL/0.5 wt\% RGO nanocomposites finishing cooling crystallization with shear at the shear rates of $3 \mathrm{~s}^{-1}$ and $75 \mathrm{~s}^{-1}$ and the shear temperatures of $65^{\circ} \mathrm{C}, 70{ }^{\circ} \mathrm{C}$ and $75{ }^{\circ} \mathrm{C}$. 


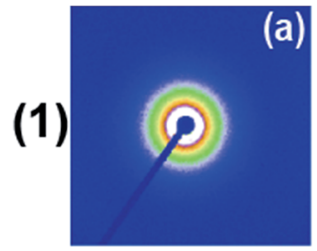

(2)

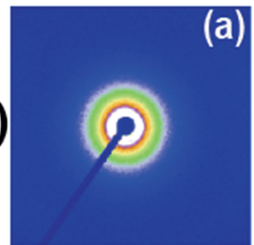

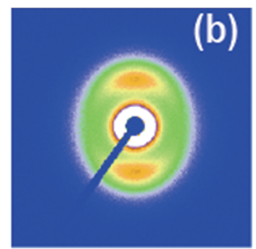

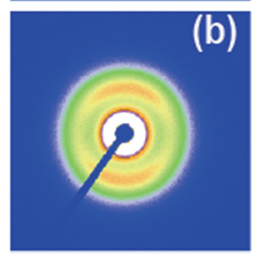

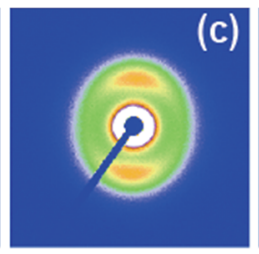

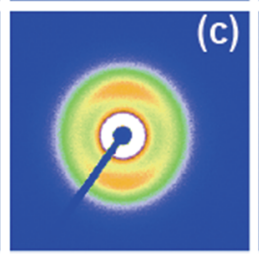

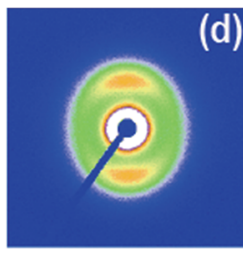

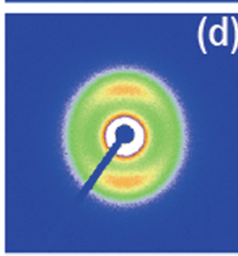

\section{Flow} direction

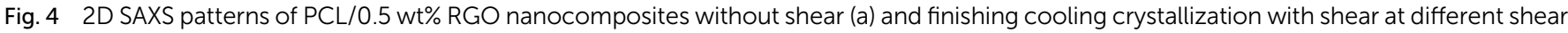
rates (1) $3 \mathrm{~s}^{-1}$, (2) $75 \mathrm{~s}^{-1}$ and different shear temperatures (b) $65^{\circ} \mathrm{C}$, (c) $70{ }^{\circ} \mathrm{C}$ and (d) $75^{\circ} \mathrm{C}$. The flow direction is vertical.

$16.40 \mathrm{~nm}, 16.10 \mathrm{~nm}$ and $16.00 \mathrm{~nm}$ at the shear temperatures of $65{ }^{\circ} \mathrm{C}, 70{ }^{\circ} \mathrm{C}$ and $75{ }^{\circ} \mathrm{C}$, respectively, which have no obvious distinctions with increasing shear temperatures, suggesting regular aligned crystal lamellae in PCL matrix. On the basis of the crystallization degree mentioned above in Fig. 3, the thickness of lamellae is calculated to be $9.00 \mathrm{~nm}, 9.16 \mathrm{~nm}$, and $9.34 \mathrm{~nm}$ at the shear temperatures of $65{ }^{\circ} \mathrm{C}, 70{ }^{\circ} \mathrm{C}$ and $75{ }^{\circ} \mathrm{C}$, respectively, which increases slightly with the shear temperatures. However, the long periods of PCL/RGO nanocomposites sheared at the shear rate of $75 \mathrm{~s}^{-1}$ and the shear temperatures of $65{ }^{\circ} \mathrm{C}, 70{ }^{\circ} \mathrm{C}$ and $75{ }^{\circ} \mathrm{C}$ are $16.80 \mathrm{~nm}, 16.60 \mathrm{~nm}$ and $16.30 \mathrm{~nm}$, which have no obvious distinctions with increasing the shear temperatures, suggesting regular aligned crystal lamellae in PCL matrix. On the basis of the aforementioned result in this paper, the thickness of lamellae is $9.13 \mathrm{~nm}, 9.21 \mathrm{~nm}$ and $9.01 \mathrm{~nm}$ at the shear temperatures of $65{ }^{\circ} \mathrm{C}, 70{ }^{\circ} \mathrm{C}$ and $75{ }^{\circ} \mathrm{C}$, respectively, not increasing with the shear temperature monotonically. From the above analysis on the effects of shear rate and shear temperature on epitaxial crystallization of PCL chains on RGO surface, we can find that the shear rate of $3 \mathrm{~s}^{-1}$ is much better for PCL chains to epitaxially crystallize on RGO surface than the shear rate of $75 \mathrm{~s}^{-1}$. This result is accord with the WAXD analysis that the crystallization degrees and the orientation degrees of (110) plane of PCL/RGO nanocomposites sheared at the shear rate of $3 \mathrm{~s}^{-1}$ are higher than those sheared at the shear rate of $75 \mathrm{~s}^{-1}$. There is no deny that the imposed shear field can enhance epitaxial crystallization of PCL chains on RGO surface, and the effect of the shear rate on epitaxial crystallization of PCL on RGO is much greater than shear temperature in the imposed shear field.

\subsection{DSC analysis}

Fig. 7 shows the DSC curves of PCL/RGO nanocomposites without shear and with shear at the shear rates of $3 \mathrm{~s}^{-1}$ and $75 \mathrm{~s}^{-1}$ and different shear temperatures of $65{ }^{\circ} \mathrm{C}, 70{ }^{\circ} \mathrm{C}$ and $75{ }^{\circ} \mathrm{C}$, respectively. Distinctions exist in the melt points of PCL/ RGO nanocomposites sheared at the shear rates of $3 \mathrm{~s}^{-1}$ and $75 \mathrm{~s}^{-1}$ comparing with that without shear. Seen from Fig. 7(1), the melt points of PCL/RGO nanocomposites sheared at the shear rate of $3 \mathrm{~s}^{-1}$ and shear temperatures of $65{ }^{\circ} \mathrm{C}, 70{ }^{\circ} \mathrm{C}$ and $75{ }^{\circ} \mathrm{C}$ are $63.36{ }^{\circ} \mathrm{C}, 63.41{ }^{\circ} \mathrm{C}$ and $63.50{ }^{\circ} \mathrm{C}$, respectively, increasing with shear temperatures, which is due to the fact that the imposed shear field makes PCL chains form thicker lamellae with increasing the shear temperatures. Seen from Fig. 7(2), the melt points of PCL/RGO nanocomposites sheared
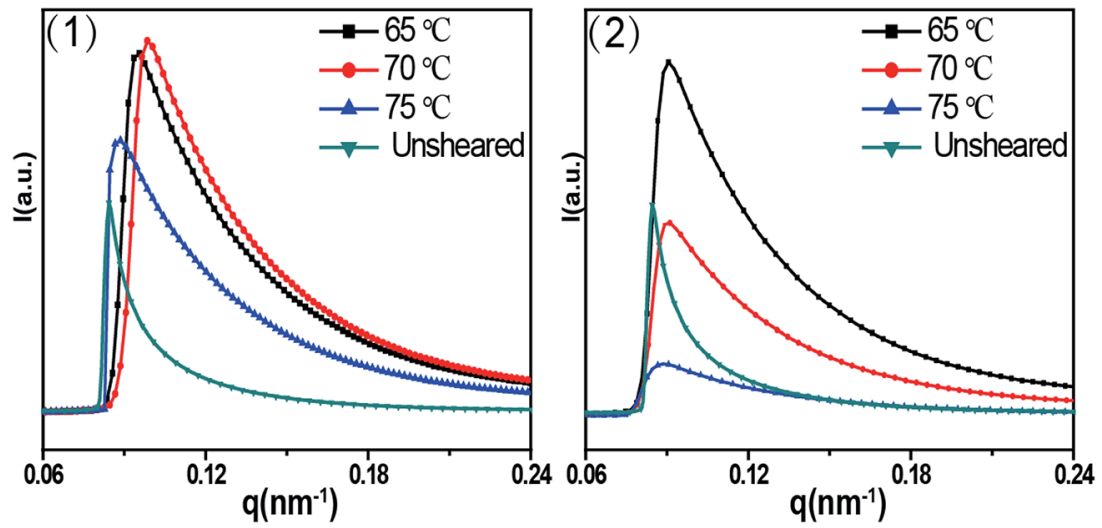

Fig. 5 1D SAXS intensity profiles radially integrated of the inner ring at different shear temperatures: (1) the shear rate of $3 \mathrm{~s}^{-1}$, (2) the shear rate of $75 \mathrm{~s}^{-1}$. 

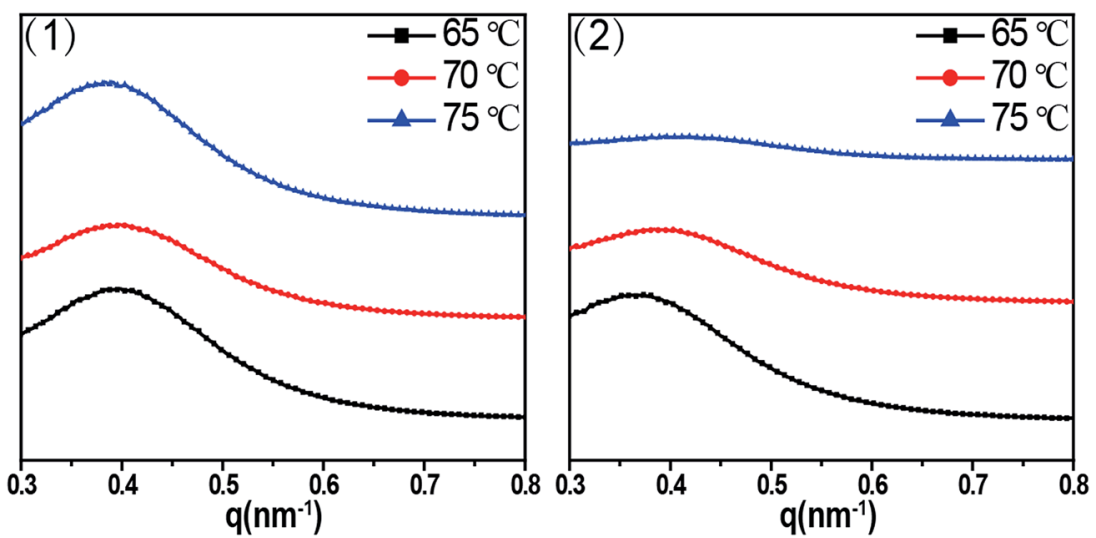

Fig. 6 1D SAXS intensity profile radially integrated of the shear rates (1) $3 \mathrm{~s}^{-1}$ (2) $75 \mathrm{~s}^{-1}$ at different shear temperatures of $65^{\circ} \mathrm{C}, 70{ }^{\circ} \mathrm{C}$ and $75^{\circ} \mathrm{C}$.

at $75 \mathrm{~s}^{-1}$ and above three shear temperatures are $62.90{ }^{\circ} \mathrm{C}$, $63.00{ }^{\circ} \mathrm{C}$ and $62.64{ }^{\circ} \mathrm{C}$, not increasing with the shear temperatures monotonically. This is because that PCL chains sheared at $75 \mathrm{~s}^{-1}$ undergo different polymer chains transition with increasing shear temperatures. PCL chains have potential to undergo random coil to stretched chains transition ${ }^{55}$ with increasing shear temperatures from $65^{\circ} \mathrm{C}$ to $70{ }^{\circ} \mathrm{C}$, as the shear temperature increases to $75^{\circ} \mathrm{C}$, PCL chains then transformed to random coil. However, the melt point of PCL/RGO nanocomposites without shear is $62.14{ }^{\circ} \mathrm{C}$, and it is below that of samples with shear, which is due to the fact that the imposed shear field makes PCL chains better epitaxially crystallization on RGO surface and form thicker lamellae. This result is in accord with the analysis of 2D WAXD patterns 2D SAXS patterns.

2D WAXD, 2D SAXS and DSC results show that the imposed shear field has great effects on epitaxial crystallization of PCL chains on RGO. The imposed shear field increases the nucleation density and mainly affects the crystallization process, ${ }^{56}$ and the orientation of PCL chains on RGO surfaces. The higher oriented PCL chains can easily epitaxially crystallize on RGO surface. As for PCL/RGO nanocomposites, the shear rate of $3 \mathrm{~s}^{-1}$ has more advantages over the shear rate of $75 \mathrm{~s}^{-1}$ for PCL chains epitaxially crystallization on RGO surface. This is because that the higher shear rate of $75 \mathrm{~s}^{-1}$ makes the melt viscosity of PCL/ RGO nanocomposites low so that it cannot offer enough time for PCL chains to adjust conformation. When PCL/RGO nanocomposites were sheared at the shear rate of $3 \mathrm{~s}^{-1}$, the higher shear temperature makes oriented polymer chains move acutely so that they can undergo random coil to stretched chains transition, namely, the higher shear temperature is more beneficial for PCL chains to epitaxially crystallize on RGO surface. Eventually, the thickness of lamella, the orientation degrees, the crystallinity and the melt points of PCL/RGO nanocomposites increase with the shear temperatures. However, PCL chains sheared at the shear rate of $75 \mathrm{~s}^{-1}$ have more potential to undergo random coil to stretched chains transition with increasing shear temperatures from $65{ }^{\circ} \mathrm{C}$ to $70{ }^{\circ} \mathrm{C}$, but the higher shear temperature of $75{ }^{\circ} \mathrm{C}$ makes PCL chains move acutely to relax, causing PCL chains undergo stretched chains to random coil transition, and then destroyed the conformation adjustment of PCL chains. The thickness of lamella, the crystallinity, the orientation degrees and the melt points of PCL/RGO nanocomposites sheared at the shear temperature of $70{ }^{\circ} \mathrm{C}$ come to the maxima. Thus, $70{ }^{\circ} \mathrm{C}$ is the best shear temperature among the three shear temperatures for PCL chains epitaxial crystallization moderately on RGO surface at $75 \mathrm{~s}^{-1}$. According to the above analysis, we can conclude that higher shear temperature is the requirement for PCL chains epitaxially crystallizing well on RGO at low shear rate, although it is not required for the samples at high shear rate.
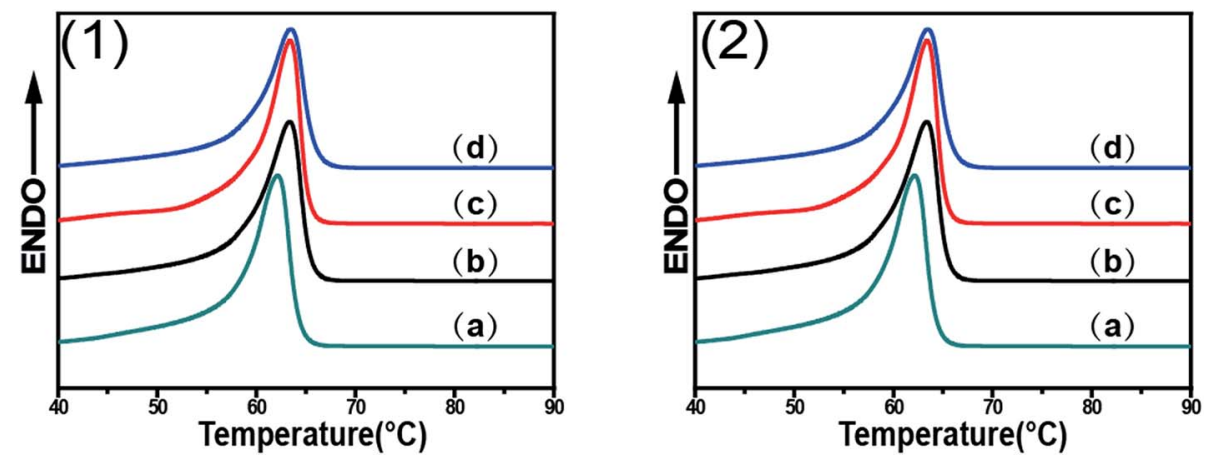

Fig. 7 DSC curves of PCL/0.5 wt\% RGO nanocomposites without shear (a) and finishing cooling crystallization with shear at different shear rates (1) $3 \mathrm{~s}^{-1}$ (2) $75 \mathrm{~s}^{-1}$ and different shear temperatures (b) $65^{\circ} \mathrm{C}$, (c) $70{ }^{\circ} \mathrm{C}$ and (d) $75^{\circ} \mathrm{C}$. 


\section{Conclusion}

The effects of shear on epitaxial crystallization of PCL/RGO nanocomposites have been investigated by WAXD, SAXS and DSC measurements. Results show that the imposed shear field has great effects on epitaxial crystallization of PCL chains on RGO surface. The shear rates of $3 \mathrm{~s}^{-1}$ and $75 \mathrm{~s}^{-1}$ and shear temperatures of $65{ }^{\circ} \mathrm{C}, 70{ }^{\circ} \mathrm{C}$ and $75{ }^{\circ} \mathrm{C}$ have different effects on epitaxial crystallization of PCL chains on RGO surface. As for effect of shear rate, the shear rate of $3 \mathrm{~s}^{-1}$ is better than the shear rate of $75 \mathrm{~s}^{-1}$ for PCL chains to epitaxially crystallize on RGO surface since the low shear rate of $3 \mathrm{~s}^{-1}$ makes PCL chains have more potential to form stretched chains. PCL/RGO nanocomposites sheared at the shear rate of $3 \mathrm{~s}^{-1}$ make PCL chains undergo random coil to stretched chains transition with the increasing shear temperatures, enhancing the epitaxial crystallization of PCL chains on RGO surface. This rule is also followed by the samples sheared at $75 \mathrm{~s}^{-1}$ and shear temperatures of $65{ }^{\circ} \mathrm{C}$ and $70{ }^{\circ} \mathrm{C}$. But stretched PCL chains transformed to random coil again as increasing the shear temperature from $70{ }^{\circ} \mathrm{C}$ to $75{ }^{\circ} \mathrm{C}$. To further study how the imposed shear field affects epitaxial crystallization of PCL chains on RGO surface, in situ synchrotron experiment is ongoing.

\section{Conflicts of interest}

There are no conflicts to declare.

\section{Acknowledgements}

This work was supported by the National Science Foundation of China (U1532114, 51773101), and K. C. Wong Magna Fund in Ningbo University. We thank Shanghai Synchrotron Radiation Facility (SSRF) for supporting the SAXS test.

\section{References}

1 L. R. Liang, C. Y. Gao, G. M. Chen and C. Y. Guo, J. Mater. Chem. C, 2016, 4, 526-532.

2 M. Rahmat and P. Hubert, Compos. Sci. Technol., 2011, 72, 72-84.

3 B. Na, Q. Zhang, Q. Fu, G. Zhang and K. Z. Shen, Polymer, 2002, 43, 7367-7376.

4 T. X. Liu, K. P. Lim, W. C. Tjiu, K. P. Pramoda and Z. K. Chen, Polymer, 2003, 44, 3529-3535.

5 D. H. Gray, S. L. Hu, E. Juang and D. L. Gin, Adv. Mater., 1997, 9, 731-736.

6 M. Rahmat and P. Hubert, Compos. Sci. Technol., 2011, 72, 72-84.

7 S. Joly, G. Garnaud, R. Ollitrault, L. Bokobza and J. E. Mark, Chem. Mater., 2002, 14, 4202-4208.

8 J. Carretero-Gonzalez, H. Retsos, R. Verdejo, S. Toki, B. S. Hsiao and E. P. gianelis, Macromolecules, 2008, 41, 6763-6772.

9 K. S. Novoselov, A. K. Geim, S. V. Morozov, D. Jiang, Y. Zhang, S. V. Dubonos, I. V. Grigorieva and A. A. Firsov, Science, 2004, 306, 666 .
10 C. Lee, X. Wei, J. W. Kysar and J. Hone, Science, 2008, 321, 385.

11 C. Peng, W. B. Hu, Y. T. Zhao, C. H. Fan and Q. Huang, Small, 2010, 6, 1686-1692.

12 J. J. Ma, Y. Li, X. D. Yin, Y. Xu, J. Yue, J. J. Bao and T. Zhou, RSC Adv., 2016, 6, 49448-49458.

13 Z. J. Wang, F. Cheng, T. Winsor and Y. M. Liu, Nanotechnology, 2016, 27, 412001.

14 K. L. Xu, G. M. Chen and D. Qiu, J. Mater. Chem. A, 2013, 1, 12395-12399.

15 C. Y. Gao and G. M. Chen, Compos. Sci. Technol., 2016, 124, 52-70.

16 H. Kim, A. A. Abdala and C. W. Macosko, Macromolecules, 2010, 43, 6515.

17 T. Kuilla, S. Bhadra, D. Yao, N. Kim, S. Bose and J. Lee, Prog. Polym. Sci., 2010, 35, 1350.

18 R. Verdejo, M. M. Bernal, L. J. Romasanta and M. A. LopezManchado, J. Mater. Chem., 2011, 21, 3301.

19 J. B. Zhang and Z. B. Qiu, Ind. Eng. Chem. Res., 2011, 50, 13885.

20 X. J. Jing and Z. B. Qiu, Ind. Eng. Chem. Res., 2012, 51, 13686.

21 H. S. Wang and Z. B Qiu, Thermochim. Acta, 2012, 527, 40.

22 B. Wang, Y. Zhang, J. Zhang, Q. Gou, Z. Wang, P. Chen and Q. Gu, Chin. J. Polym. Sci., 2013, 31, 670.

23 E. Bekyarova, M. E. Itkis, P. Ramesh, C. Berger, M. Sprinkle, W. A. Herr and R. C. Haddon, J. Am. Chem. Soc., 2009, 131, 1336.

24 C. Shan, H. Yang, D. Han, Q. Zhang, A. Ivaska and A. Niu, Langmuir, 2009, 25, 12030.

25 H. J. Salavagione, M. A. Gomez and G. Martinez, Macromolecules, 2009, 42, 6331.

26 Q. Yang, X. J. Pan, K. Clarke and K. C. Li, Ind. Eng. Chem. Res., 2012, 51, 310.

27 S. Niyogi, E. Bekyarova, M. E. Itkis, J. L. McWilliams, M. A. Hamon and R. C. Haddon, J. Am. Chem. Soc., 2006, 128, 7720.

28 J. T. Paci, T. Belytschko and G. C. Schatz, J. Phys. Chem. C, 2007, 111, 18099.

29 N. Y. Ning, S. R. Fu, W. Zhang, F. Chen, K. Wang and H. Deng, Prog. Polym. Sci., 2012, 37, 1425-1455.

30 G. B. Yao, T. C. Duan, M. F. An, H. Xu, F. Tian and Z. B. Wang, RSC Adv., 2017, 7, 21918-21925.

31 T. Kuilla, S. Bhadra, D. Yao, N. Kim, S. Bose and J. Lee, Prog. Polym. Sci., 2010, 35, 1350-1375.

32 J. Petermann, G. Broza, U. Rieck and A. Kawaguchi, J. Mater. Sci., 1987, 22, 1477-1481.

33 J. Petermann and Y. Xu, Colloid Polym. Sci., 1991, 269, 455459.

34 B. Gross and J. Petermann, J. Mater. Sci., 1984, 19, 105-112. 35 F. Tuinstra and E. Baer, J. Polym. Sci., Part B: Polym. Phys., 1970, 8, 861-865.

36 B. J. Wang, Y. G. Li, G. S. Weng, Z. Q. Jiang, P. Chen, Z. B. Wang and Q. Gu, Compos. Sci. Technol., 2014, 96, 63-70.

37 B. J. Wang, Y. J. Zhang, J. Q. Zhang, H. Y. Li, P. Chen, Z. B. Wang and Q. Gu, Ind. Eng. Chem. Res., 2013, 52, 15824-15828.

38 H. Li and S. Yan, Macromolecules, 2011, 44, 417-428. 
39 S. K. Yan, D. C. Yang and J. Petermann, Polymer, 1998, 39, 4569-4578.

40 S. K. Yan, J. Petermann and D. C. Yang, Polymer, 1996, 37, 2681-2685.

41 Y. J. Sun, H. H. Li, Y. Huang, E. Chen, L. Zhao, Z. H. Gan and S. K. Yan, Polymer, 2006, 47, 2455-2459.

42 L. Cartier, T. Okihara, Y. Ikada, H. Tsuji, J. Puiggali and B. Lotz, Polymer, 2000, 41, 8909-8919.

43 W. Cao, K. Wang, Q. Zhang, R. N. Du and Q. Fu, Polymer, 2006, 47, 6857-6867.

44 H. Janeschitz-kriegl, E. Ratajski and M. Stadlbauer, Rheol. Acta, 2003, 42, 355-364.

45 B. J. Luo, H. F. Li, W. Y. Zhang, C. B. Zhou, J. Q. Li, C. H. Lu, X. H. He and S. C. Jiang, Chin. J. Polym. Sci., 2017, 35, 672680.

46 A. Kelarakis, K. Yoon, I. Sics, R. H. Somani, X. M. Chen and B. S. Hsiao, J. Macromol. Sci., Part B: Phys., 2006, 45, 247-261. 47 R. Su, K. Wang and P. Zhao, Polymer, 2007, 48, 4529-4536.
48 Y. Wang, Z. H. Li, D. H. Hu, C. T. Lin, J. H. Li and Y. H. Lin, J. Am. Chem. Soc., 2010, 132, 9274-9276.

49 B. J. Wang, H. Y. Li, L. Z. Li, P. Chen, Z. B. Wang and Q. Gu, Compos. Sci. Technol., 2013, 89, 180-185.

50 R. H. Somani, B. S. Hsiao, A. Nogales, S. Srinivas, A. H. Tsou and I. Sics, Macromolecules, 2000, 33, 9385.

51 A. Nogales, B. S. Hsiao, R. H. Somani, S. Srinivas, A. H. Tsou and F. J. Balta-Calleja, Polymer, 2000, 42, 5247.

52 R. H. Somani, L. Yang and B. S. Hsiao, Polymer, 2006, 47, 5657-5668.

53 A. P. Hammersley, S. O. Svensson and A. Thompson, Nucl. Instrum. Methods Phys. Res., 1994, 346, 312-321.

54 L. E. Alexander, J. Polym. Sci., Part B: Polym. Lett., 1969, 10, 1002.

55 PCL stretched chains herein are higher orientated than random coils, which have more advantage over random coils to epitaxially crystallize on RGO surface.

56 D. Lellinger, G. Floudas and I. Alig, Polymer, 2003, 44, 57595769. 